\title{
Is premigration health screening for tuberculosis worthwhile?
}

\section{Kathleen King \\ BSc(Hons) MB ChB, \\ FRCPath, Formerly Senior \\ Medical Adviser \\ Paul J Douglas MB BS, MHA, FRACMA Chief Medical Officer and Global Manager Health, Immigration \\ Ken Beath \\ BE, MAppStat, PhD Lecturer $^{2}$}

1 Global Health Branch, Department of Immigration and Citizenship Sydney, NSW.
SSW

2 Department of Statistics, Macquarie University, Sydney, NSW.

paul.douglas@ immi.gov.au

MJA 2011; 195: 534-537 doi: 10.5694/mjal0.11395 uberculosis remains a disease of importance to public health in Australia, ${ }^{1}$ although its annual incidence rate of 6.2 per 100000 population is one of the lowest in the world. ${ }^{2}$ In 2007, 1135 cases of tuberculosis were notified in Australia; $86.4 \%$ of cases occurred in people born overseas. ${ }^{3}$

Tuberculosis is the only disease specifically mentioned in the Migration Regulations 1989 (Cwlth), and health screening for immigration purposes has focused closely on its detection and treatment overseas, before migrants arrive in Australia. In spite of a large influx over the past 20 years of migrants from countries with incidence rates 10-100 times higher than Australia's, the annual incidence rate of tuberculosis in Australia has remained steady at around 5-6 per 100000 population. ${ }^{3}$ The Australian National Tuberculosis Advisory Committee has attributed the consistently low incidence rate largely to effective premigration screening and treatment offshore, and to specialised tuberculosis services onshore. ${ }^{4}$

Accurate information has not previously been readily available on the numbers and source countries of people with active tuberculosis who are detected by immigration health screening and prevented from entering Australia until they have been treated. Here, we present data derived from the immigration health screening process to examine the value of premigration screening for tuberculosis.

\section{Methods}

\section{Premigration screening for tuberculosis}

To be granted a visa, intending permanent and temporary residents aged 11 years or older are required to undergo a chest $x$-ray and, except for some temporary residents, a medical examination before arriving in Australia. Children aged under 11 years are required to have a medical

Abstract

Objective: To determine whether premigration screening for tuberculosis is worth undertaking in visa applicants, and whether screening resources are being appropriately directed towards intending migrants at highest risk of tuberculosis.

Design, setting and participants: A 12-month survey of all intending migrants with tuberculosis necessitating treatment detected during the premigration health assessment process, whose medical examinations were submitted to the Department of Immigration and Citizenship's Global Health Branch for assessment by a Medical Officer of the Commonwealth between 1 July 2009 and 30 June 2010.

Main outcome measures: Individuals diagnosed with active tuberculosis; proportions diagnosed by sputum smear and culture tests or clinically, and with susceptibility test results; distribution of visa types among people diagnosed.

Results: In premigration assessments, 519 people were diagnosed with active tuberculosis (prevalence, 137 per 100000 in examined population). The top source countries for people with tuberculosis were the Philippines (21.8\%), India (16.8\%), Vietnam (16.2\%) and China (8.3\%). Positive sputum smear test results were submitted for 67 cases (12.9\%). Positive culture test results were obtained in 230 cases (44.3\%), but only 95 of these (41.3\%) had susceptibility test results, with 83 fully susceptible. Four people had multidrug-resistant tuberculosis (prevalence, 1.06 per 100000 population). Five people had both active tuberculosis and HIV infection. Of all those diagnosed with tuberculosis, $162(31.2 \%)$ were intending students, $82(15.8 \%)$ were intending visitors, and 53 $(10.2 \%)$ were applicants for humanitarian (refugee and Special Humanitarian Program) visas.

Conclusions: Premigration health screening of intending migrants is identifying substantial numbers of people who would have required treatment for tuberculosis after arrival in Australia. The high proportion of students, visitors and refugee and humanitarian entrants with tuberculosis validates the current screening program. The screening is of benefit to the applicants, whose tuberculosis is treated earlier than it otherwise would have been, and to the Australian population, by averting exposure to people with active tuberculosis.

examination for permanent residency, and sometimes for temporary residency, and may also have a chest $\mathrm{x}$-ray if deemed clinically appropriate. These examinations are performed by panel radiologists and doctors ${ }^{5}$ nominated and managed by the Department of Immigration and Citizenship's Global Health Branch. The examinations undertaken are determined by a health matrix based on risk-management principles, dependent on the purpose and proposed length of stay and the tuberculosis incidence rate in the source country. ${ }^{6}$

In cases where panel radiologists report abnormalities suggestive of tuberculosis, or in countries where there are no qualified radiologists or standards are not regarded as equivalent to those in Australia, examinations are referred to the Global Health Branch for evaluation by a
Medical Officer of the Commonwealth (MOC).

Cases are evaluated according to departmental guidelines, ${ }^{7}$ and MOCs request sputum smear and culture tests for all applicants with suspected tuberculosis. Cases are reported from a wide range of countries with differing methods and limitations on undertaking tuberculosis testing: culture tests may not be available, smear and culture testing may be offered but of variable quality, or a full array of high-quality smear and culture tests and susceptibility testing may be obtainable.

\section{Diagnosis of active tuberculosis}

The investigation (and potentially treatment) of visa applicants suspected of having tuberculosis may be undertaken by a panel doctor or chest physician with sputum smear and culture tests before documentation is for- 
warded to an MOC. In situations where further investigation or treatment of applicants with suspected tuberculosis has not commenced, MOCs request results of sputum smear and culture tests and further chest $\mathrm{x}$-rays after sufficient time has elapsed to prove stability of chest $x$-ray changes (no sooner than 3-6 months).

For this study, individuals were considered to have active tuberculosis if:

- they had positive results of one or more sputum smear tests for acidand alcohol-fast bacilli;

- they had a positive result of one or more sputum culture tests for Mycobacterium tuberculosis;

- a chest or other physician had recommended antituberculous treatment, or if they had undergone such treatment, as a result of abnormalities in the premigration chest $x$-ray (regardless of negative results of smear or culture tests); or

- their chest $\mathrm{x}$-rays were considered by an MOC to show progression of disease compatible with active tuberculosis (regardless of negative results of smear or culture tests).

The results of other tests for $M$. tuberculosis, such as nucleic-acid tests, are accepted when provided but not routinely requested because of the cost to applicants and widespread lack of availability of validated testing.

\section{Data collected}

For this study, we included all individuals with suspected or proven pulmonary or extrapulmonary tuberculosis whose cases were submitted to an MOC for evaluation between 1 July 2009 and 30 June 2010, and found to require or to have required treatment for tuberculosis during the migration process.

For every identified case of active tuberculosis, MOCs entered data on a spreadsheet including age, sex, country of location, visa class sought, and results of smear, culture and susceptibility tests where supplied. Country of location was chosen over country of birth to better target future MOC liaison visits to assist panel doctors with managing the tuberculosis risk in premigration processing.

Numbers of health examinations performed overseas by panel members were obtained from two Depart- ment of Immigration and Citizenship databases: 5 months (November 2009 to March 2010) of data from one database and 8 months (July 2009 to February 2010) from another. The total estimated number of applicants for the 2009-10 financial year was extrapolated from these data. Based on historical data, these extrapolations are believed to be reasonably accurate.

As all data were de-identified and collected as part of normal management practice within the Department of Immigration and Citizenship, ethics approval was not sought for this study.

\section{Statistical analysis}

Statistical analysis was performed using R 2.12.0 (R Project for Statistical Computing, http://www.rproject.org). Proportions between countries were compared using a $\chi^{2}$ test, with $P$ values obtained through simulation.

\section{Results}

In an estimated 378939 people who underwent premigration medical examinations during the 2009-10 financial year, 519 cases of active tuberculosis were detected (Box 1), giving a prevalence in the examined population of 137.0 per 100000 . The top four source countries for people with tuberculosis were the Philippines (113; $21.8 \%)$, India (87; $16.8 \%)$, Vietnam (84; $16.2 \%$ ) and China (43; 8.3\%) (Box 2).

There was a significant difference between the top 10 source countries in the prevalence of tuberculosis among the examined population $(P<0.001)$ (Box 3). The highest prevalences were in Vietnam, Cambodia and the Philippines. We found significantly lower prevalences in India, China, South Korea, Indonesia and Thailand than those reported by the World Health Organization, whereas the other five countries had up to double the prevalence reported by the WHO. ${ }^{2}$

Of the 519 people with active tuberculosis, only $67(12.9 \%)$ had positive results of sputum smear tests (Box 2). In 230 cases (44.3\%), positive culture test results were obtained, and in 95 of these $(41.3 \%)$, the results of susceptibility tests were provided.

In 262 cases (50.5\%), the diagnosis of tuberculosis was made only clinically because smear and culture test results
1 Individuals with active tuberculosis, by age and sex

\begin{tabular}{lccc}
$\begin{array}{l}\text { Age } \\
\text { (years) }\end{array}$ & Male & Female & All \\
\hline $0-9$ & 5 & 2 & 7 \\
$10-19$ & 34 & 29 & 63 \\
$20-29$ & 82 & $116(1 *)$ & $198(1 *)$ \\
$30-39$ & 48 & $51\left(3^{*}\right)$ & $99\left(3^{*}\right)$ \\
$40-49$ & 28 & $29(1 *)$ & $57(1 *)$ \\
$50-59$ & 14 & 15 & 29 \\
$60-69$ & 20 & 18 & 38 \\
\hline 70 & 19 & 9 & 28 \\
\hline Total & 250 & 269 & 519 \\
\hline *Also has HIV infection. & & \\
\hline
\end{tabular}

were negative or could not be obtained, but the clinician believed the individual had disease warranting treatment (Box 2). In 23 clinically diagnosed cases (4.4\% of all cases), no cultures were undertaken (mainly in the Philippines), and in $26(5.0 \%)$, no sputum samples were assessed because the individuals were not able to produce them or because they had a diagnosis of tuberculous lymphadenitis. Six people (1.2\%) had non-pulmonary tuberculosis. There was a significant difference among the top 10 source countries in the proportions diagnosed clinically $(P<0.001)$, ranging from $14 \%$ in Cambodia to $93 \%$ in Indonesia.

Of the 95 isolates tested for susceptibility, 83 were fully susceptible (Box 2). Four people had multidrug-resistant tuberculosis (MDR-TB) (prevalence, 1.06 per 100000 population). Three had proven MDR-TB: one from each of the Philippines, Burma and Vietnam. A chest physician reported that another person from the Philippines was being treated for MDR-TB, but susceptibility results were not provided despite a positive sputum culture test result.

Most people (382; 73.6\%) diagnosed with tuberculosis had undergone concomitant or subsequent HIV testing. Five women tested positive for HIV (Box 2): four had tuberculosis diagnosed only clinically, and one had positive results of both smear and culture tests.

Of all 519 people diagnosed with tuberculosis, 162 (31.2\%) were intending students, $82(15.8 \%)$ were intending visitors, and 53 (10.2\%) were applicants for humanitarian (refugee and Special Humanitarian Program) visas. 
The overseas screening program is detecting substantial numbers of people with active tuberculosis who otherwise would have travelled to Australia. Premigration screening detected 519 people who required treatment for active tuberculosis in the 2009-10 financial year. It is uncertain if this is typical, although at May 2011 nearly 400 cases had been identified in the 2010-11 program year. The prevalence of tuberculosis we found (137 per 100000 population) compares with that found in people in Australian immigration reception and processing centres (157 per 100000$){ }^{8}$ These rates are high compared with the estimated prevalence of tuberculosis in Australia of 7.9 per 100000 population in $2009 .^{2}$

The screening program is protecting the public health of the Australian community and decreasing costs that may have been incurred if diagnosis and treatment had been delayed until arrival in Australia. Based on Australian $^{7}$ and British ${ }^{9}$ data, estimated costs for tuberculosis care and treatment are at least $\$ 10000$ with a fully sensitive organism, \$200 per contact for tracing, and at least $\$ 100000$ for treatment of individuals with MDR-TB. Australian data suggest hospitalisation costs of at least $\$ 20000$ for each person requiring admission to hospital for isolation.?

Our finding that only $1.2 \%$ of cases were non-pulmonary tuberculosis contrasts with a Victorian study, in which $45 \%$ of 3191 laboratory-confirmed cases of tuberculosis diagnosed between 1990 and 2004 were non-pulmonary tuberculosis. ${ }^{10}$ We postulate that panel doctors may have overlooked palpable nodes, or that the low rate is related to a large proportion of examinations being chest $\mathrm{x}$-ray only.

Intending students and visitors represented $47 \%$ of tuberculosis cases in our study. Education bodies (eg, migration agents, business and recruitment groups) and tourism bodies have suggested that the medical examination requirements ${ }^{6}$ are onerous and costly for those intending temporary residence, but our results indicate they are warranted in terms of case-finding

2 Tuberculosis cases by location, results of sputum smear and culture tests, susceptibility, and clinical diagnosis

\begin{tabular}{|c|c|c|c|c|c|c|}
\hline \multirow[b]{2}{*}{ Location of applicant } & \multirow[b]{2}{*}{ Cases } & \multicolumn{3}{|c|}{ Positive sputum test } & \multirow[b]{2}{*}{$\begin{array}{l}\text { Susceptible } \\
\text { (resistant) }\end{array}$} & \multirow[b]{2}{*}{$\begin{array}{l}\text { Clinical } \\
\text { diagnosis* }\end{array}$} \\
\hline & & $\begin{array}{c}\text { Smear } \\
\text { only }\end{array}$ & $\begin{array}{c}\text { Culture } \\
\text { only }\end{array}$ & $\begin{array}{c}\text { Smear and } \\
\text { culture }\end{array}$ & & \\
\hline Afghanistan & 3 & 0 & 0 & 0 & - & 3 \\
\hline Bangladesh & 8 & 1 & 4 & 0 & - & 3 \\
\hline Burma & 5 & 1 & 0 & 1 & $-\left(1^{\dagger}\right)$ & 3 \\
\hline Cambodia & 14 & 1 & 10 & 1 & - & 2 \\
\hline China & 43 & 1 & 14 & 2 & 2 & 26 \\
\hline Djibouti & 1 & 0 & 0 & 0 & - & 1 \\
\hline East Timor & 3 & 0 & 0 & 0 & - & 3 \\
\hline Egypt & 3 & 0 & 1 & 0 & - & 2 \\
\hline Ethiopia & 3 & 1 & 0 & 0 & - & 2 \\
\hline Fiji & 1 & 0 & 0 & 0 & - & 1 \\
\hline Ghana & 2 & 1 & 1 & 0 & - & 0 \\
\hline Guinea & 8 & 0 & 5 & 0 & - & 3 \\
\hline Hong Kong & 3 & 1 & 0 & 0 & - & 2 \\
\hline India & $87\left(2^{\ddagger}\right)$ & 2 & 24 & 2 & 3 & $59^{5}$ \\
\hline Indonesia & 15 & 1 & 0 & 0 & - & 14 \\
\hline Italy & 1 & 0 & 1 & 0 & - & 0 \\
\hline Japan & 1 & 0 & 0 & 1 & 1 & 0 \\
\hline Kenya & 10 & 0 & 6 & 2 & 7 & 2 \\
\hline Laos & $1^{\ddagger}$ & 0 & 0 & 0 & - & 1 \\
\hline Malaysia & 20 & 0 & 8 & 0 & 4 & 12 \\
\hline Nepal & 12 & 0 & 5 & 2 & 4 & 5 \\
\hline New Zealand & 4 & 0 & 4 & 0 & 4 & 0 \\
\hline Pakistan & 11 & 2 & 4 & 0 & 2 & 5 \\
\hline The Philippines & 113 & 4 & 43 & 13 & $40\left(9^{9}\right)$ & 53 \\
\hline Russia & 1 & 1 & 0 & 0 & - & 0 \\
\hline Singapore & 3 & 0 & 2 & 0 & - & 1 \\
\hline South Africa & $3\left(1^{\ddagger}\right)$ & 0 & 0 & 0 & - & 3 \\
\hline South Korea & 24 & 2 & 8 & 2 & 2 & 12 \\
\hline Sri Lanka & 2 & 1 & 1 & 0 & - & 0 \\
\hline Sudan & 1 & 0 & 0 & 0 & - & 1 \\
\hline Syria & 1 & 0 & 0 & 0 & - & 1 \\
\hline Taiwan & 1 & 0 & 0 & 0 & - & 1 \\
\hline Thailand & 13 & 0 & 2 & 1 & 2 & 10 \\
\hline Togo & 1 & 0 & 0 & 0 & - & 1 \\
\hline Turkey & 1 & 0 & 0 & 0 & - & 1 \\
\hline Uganda & 3 & 0 & 1 & 2 & 2 & 0 \\
\hline Ukraine & 1 & 0 & 1 & 0 & - & 0 \\
\hline United Kingdom & 5 & 0 & 2 & 0 & 2 & 3 \\
\hline Vietnam & $84\left(1^{\ddagger}\right)$ & 6 & 43 & 11 & $8(2 * *)$ & 24 \\
\hline Zimbabwe & 3 & 1 & 0 & 0 & - & 2 \\
\hline Total & $519\left(5^{\ddagger}\right)$ & 27 & 190 & 40 & $83(12)$ & 262 \\
\hline
\end{tabular}

* Smear and culture test results were negative or could not be obtained, but the clinician believed the person had disease warranting treatment. † Isoniazid + streptomycin + rifampicin-resistant. $\ddagger$ Also has HIV infection. $\$$ One diagnosed by polymerase chain reaction test on pleural fluid. G Isoniazid-resistant (7), isoniazid + streptomycin-resistant (1), isoniazid + streptomycin + rifampicin-resistant (1).**Isoniazid + streptomycin-resistant (1), isoniazid + streptomycin + rifampicin + ethambutol-resistant (1).

and minimising public health risk to the Australian community.

Our study has some limitations. Data collection was dependent on MOCs manually recording case information on a spreadsheet, and underreporting is likely to have occurred.
More than two-thirds of all medical examinations, where normal findings are reported by a panel doctor and/or radiologist, are cleared administratively without assessment by an MOC. There is a small possibility of missed active tuberculosis cases in this group, but the 


\section{Prevalence of active tuberculosis in top 10 source countries}

\begin{tabular}{lcccc} 
Country & Cases (\%) & $\begin{array}{c}\text { Estimated } \\
\text { examinations }\end{array}$ & $\begin{array}{c}\text { WHO reported } \\
\text { Prevalence* }\end{array}$ & $\begin{array}{l}\text { Prevalence* 2009 } \\
\text { pres }\end{array}$ \\
\hline The Philippines & $113(21.8 \%)$ & 12795 & 883.2 & 520 \\
India & $87(16.8 \%)$ & 59666 & 145.8 & 249 \\
Vietnam & $84(16.2 \%)$ & 13621 & 616.7 & 333 \\
China & $43(8.3 \%)$ & 71600 & 60.1 & 138 \\
South Korea & $24(4.6 \%)$ & 42503 & 56.5 & 114 \\
Malaysia & $20(3.9 \%)$ & 12859 & 155.5 & 109 \\
Indonesia & $15(2.9 \%)$ & 9192 & 163.2 & 285 \\
Cambodia & $14(2.7 \%)$ & 1512 & 925.9 & 693 \\
Thailand & $13(2.5 \%)$ & 10608 & 122.5 & 189 \\
Nepal & $12(2.3 \%)$ & 2861 & 419.4 & 240 \\
Other & $94(18.1 \%)$ & 141722 & 66.3 & - \\
Total & $519(100 \%)$ & 378939 & 137.0 & - \\
\hline
\end{tabular}

WHO $=$ World Health Organization. $*$ Cases per 100000 population.

likelihood is minimal, with regular audits of $5 \%$ of these cases finding that the error rate (where tuberculous changes have been missed on chest $\mathrm{x}$-ray) is less than $0.1 \%$ (unpublished data, Global Health Branch). Further, documents are reassessed when the Global Health Branch is informed of a case of pulmonary tuberculosis diagnosed in the first year after arrival. In $98 \%$ of such cases, the premigration chest $\mathrm{x}$-ray is normal (unpublished data, Global Health Branch).

In cases with a normal chest $\mathrm{x}$-ray deemed not to have tuberculosis by MOCs, applicants' health assessment results are valid for 12 months, during which time they may acquire or develop tuberculosis before travelling to Australia. Tuberculosis can develop very quickly in some people, going from normal appearances to florid tuberculosis in months. ${ }^{11}$

Limitations in sputum smear and culture methods meant that about half the cases were diagnosed clinically (95\% of these having negative sputum tests), compared with about $23 \%$ of cases diagnosed clinically in Australia. ${ }^{3,12}$ Thus, it is possible that tuberculosis was overdiagnosed in our study.

The proportion of cases with positive results of culture tests (44.3\%) was low compared with that in Australia (around $77 \%$ ). ${ }^{12}$ Susceptibility test results were available for less than half of these cases, compared with all such cases in Australia. ${ }^{12}$ In part, this low rate is explained by the nonavailability of susceptibility testing in many overseas locations, but it may also be due to costs of the tests, which are borne by the applicant in many positive cultures underwent susceptibility testing. This is concerning, as Indian-born patients comprised $17 \%$ of cases of MDR-TB (4/24) diagnosed in Australia in 2007. ${ }^{12}$

As HIV testing is not mandatory for temporary migration purposes, not everyone diagnosed with tuberculosis had this testing. HIV test results are requested in all cases when tuberculosis is diagnosed but are not always supplied. Nearly three-quarters of people in our study were tested for HIV antibody, but only five were found to have concomitant HIV infection; only one of these had positive laboratory results for tuberculosis.

The disparities between the prevalences we found compared with those reported by the WHO could be related to differences among applicants from individual countries. We theorise that migrants from India, China, South Korea, Indonesia and Thailand (where we found lower prevalences than reported by the WHO) may have been from a wealthier middle class, with higher numbers of refugees from other countries where we found higher prevalences than reported by the WHO.

This study has given us the opportunity to better target our efforts in improving laboratory diagnosis of tuberculosis. As part of recent liaison visits for MOCs to supervise panel doctors, MOCs are identifying selected laboratories to undertake testing for Australian visa applicants based on their ability to perform to acceptable standards. This is currently not possible to apply worldwide for all countries. In India, only three of 26 laboratories, but the Global Health Branch, in conjunction with the relevant sections in countries such as the United States and Canada, is accrediting laboratory "centres of excellence" in tuberculosis work and defining minimum standards in laboratory testing for migration purposes in countries such as the Philippines, India, Vietnam and China. Such improvement in laboratory capacity should, over time, reduce the issues of low sputum smear- and culture-positive rates and lack of susceptibility testing. Further, the planned introduction in 2012 of a new data system, "cHealth", will enable automatic capture of the data currently entered by MOCs on spreadsheets, and should assist in data aggregation and analysis.

Acknowledgements: We thank all the MOCs who contributed details of cases.

Competing interests: No relevant disclosures. Received 29 Nov 2010, accepted 4 Aug 2011

1 Bastian I, Krause VL. Tuberculosis: the dis-ease that didn't dis-appear [editorial]. Med J Aust 2008; 188: 131-132.

2 World Health Organization. Global tuberculosis control. WHO report 2010. Geneva: WHO, 2010: 183.

3 Barry C, Konstantinos A; National Tuberculosis Advisory Committee. Tuberculosis notifications in Australia, 2007. Commun Dis Intell 2009; 33 : 304-315.

4 National Tuberculosis Advisory Committee of Communicable Diseases Network Australia. National strategic plan for TB control in Australia beyond 2000. Canberra: Department of Health and Ageing, 2002. http://www.health.gov.au/ internet/main/publishing.nsf/Content/cdapubs-other-tb_plan.htm (accessed Oct 2010).

5 Department of Immigration and Citizenship. Health requirements for visa applicants. http:// www.immi.gov.au/allforms/healthrequirements (accessed Oct 2010).

6 Department of Immigration and Citizenship. Health requirement for temporary entry to Australia. Form 1163i. http://www.immi.gov.au/ allforms/pdf/1163i.pdf (accessed Oct 2010).

7 Department of Immigration and Citizenship. Notes for guidance for Medical Officers of the Commonwealth of Australia. Financial implications and consideration of prejudice to access to services associated with tuberculosis. Canberra: Commonwealth of Australia, 2010.

8 King K, Vodicka P. Screening for conditions of public health importance in people arriving in Australia by boat without authority. Med J Aust 2001; 175: 600-602.

9 White VLC, Moore-Gillon J. Resource implications of patients with multidrug resistant tuberculosis. Thorax 2000; 55: 962-963.

10 McPherson ME, Leslie D, Sievers A, et al. Epidemiology of laboratory confirmed tuberculosis in Victoria, 1990 to 2004. Commun Dis Intell 2008; 32: 237-241.

11 Lavender CJ, Brown LK, Johnson PD. Multidrugresistant tuberculosis in Victoria: a 10-year review. Med J Aust 2009; 191: 315-318.

12 Lumb R, Bastian I, Carter R, et al. Tuberculosis in Australia: bacteriologically confirmed cases and drug resistance, 2007. A report of the Australian Mycobacterium Reference Laboratory Network. Commun Dis Intell 2009; 33: 298-303. 